\title{
De la satisfacción al malestar social: abuelas cuidadoras de escolares en la Zona Metropolitana de Toluca*
}

\section{From satisfaction to social displeasure: grandmother school-age children caregivers in Toluca Metropolitan Zone}

\author{
Alejandro Martínez-Espinosa y \\ Sergio Cuauhtémoc Gaxiola Robles Linares \\ Centro de Investigación y Estudios Avanzados de la Población de la Universidad \\ Autónoma del Estado de México
}

Resumen

El envejecimiento poblacional genera la oportunidad de que convivan diferentes generaciones. De ello pueden beneficiarse tanto la niñez en su formación, como las abuelas al mantener su sensación de contribuir a la familia. Pero ello no significa que dicha convivencia se dé en los mejores términos. En este artículo se desarrolla una exploración cualitativa de nueve entrevistas semiestructuradas, para indagar las experiencias de abuelas cuidadoras de niños en edad escolar. Como resultado se identificaron experiencias que no representaban ningún esfuerzo e incluso se promovían frente a opciones institucionales, pero también hubo narrativas cargadas de una frustración indecible y de una priorización de los objetivos de los familiares. Las experiencias mostraron matices en la convivencia intergeneracional que requieren de un nuevo andamiaje institucional para la procuración del bienestar de las abuelas.

Palabras clave: Cuidados, adultos mayores, malestar social, abuelas.

Abstract

Population aging creates the opportunity for different generations' coexistence. This can benefit both children in their breeding and grandmothers by maintaining their sense of contributing to the family. On the other hand, that does not mean that coexistence occurs in the best terms. In this article, we developed a qualitative exploration of nine semi-structured interviews, to investigate the experiences of caregiver grandmothers of school-age children. As a result, we identify experiences that did not represent any effort and were even promoted against institutional options, but there were also narratives loaded with unspeakable frustration and prioritization of family members' goals. The experiences showed nuances in the intergenerational coexistence that require a new institutional scaffolding for the welfare of grandmothers.

Keywords: Care, elderly people, social displeasure, grandmothers.

* Este artículo es producto del análisis y discusión que se desarrolló a partir del proyecto de investigación titulado "Representaciones y consumos alimentarios de las poblaciones en edades escolares y en edades avanzadas del Estado de México" con clave 4571/2018/CIV desarrollado por el cuerpo académico consolidado: Procesos demográficos y política social, con registro ante la Secretaría de Educación Pública: UAEM-CA226. 


\section{INTRODUCCIÓN}

$\mathbf{E}$

1 aumento de la población con edades mayores a los 60 años ha sido acompañado por un llamado de atención a los retos que representa. Entre ellos se cuentan, la insuficiencia de recursos para atender el pago de pensiones y sistemas de retiro, el envejecimiento de la fuerza laboral y su competitividad, la fragilidad de la salud de dicha población y el cambio de relaciones familiares y las características de los hogares, la necesidad de transferencias intergeneracionales ante la insuficiencia de sus recursos, le feminización de la vejez, así como la vulnerabilidad en cada aspecto de la vida que supone el envejecer (González K., 2015).

Dentro de ese conjunto de retos, es notorio que la convivencia intergeneracional se visibiliza sólo de forma parcial, al suponer que los recursos sólo se dirigen hacia las personas mayores. Cada vez es más evidente, que el cuidado de niñas y niños puede ser una contribución muy importante para los hogares contemporáneos, lo que sin embargo, trae consigo un conjunto de implicaciones que aun requieren de un análisis, en directa relación con el hecho de que la provisión de cuidados es asumida principalmente por mujeres.

Por otro lado, para el análisis de la convivencia intergeneracional de las abuelas, puede ser de utilidad situar el andamiaje institucional que enmarca las pautas de la vida social. La retirada del Estado de la implementación de acciones que aseguren los derechos de la población, para focalizar su acción en los grupos vulnerables (bajo el argumento de su ineficacia) (Kuntz, 2012), ha tenido en las personas adultas mayores uno de sus ejemplos emblemáticos. Con todo, las transferencias monetarias aun requieren de acompañarse con acciones orientadas a la independencia, autonomía, inclusión social, y entornos domésticos adecuados para las y los adultos mayores (Yanes, 2011). Lo anterior supone también la necesidad de incrementar la evidencia respecto a las condiciones e implicaciones de la vida familiar, para cada uno de sus miembros.

En este artículo, es nuestro objetivo delinear la realidad demográfica que enmarca la vida familiar multigeneracional, como punto de partida para explorar las experiencias que enmarcan la vida en familia de las abuelas. De modo que ante el declarado fin del neoliberalismo (Morales y Moreno, 2019), señalamos en la discusión algunos aspectos que podrían mejorar ante un cambio en el modelo de desarrollo, orientados al bienestar de las abuelas. Así, más que analizar el alcance del servicio de guarderías o 
estancias infantiles o de apuntar a su necesidad, nos enfocamos en explorar las interacciones que enmarcan los cuidados efectivos que se brindan en el hogar, por parte de las abuelas.

En un primer momento, nos posicionamos frente a los roles que se construyen por cada género, así como las aportaciones para la sociedad que conlleva el cuidado de escolares. Posteriormente, nos avocamos a entender los arreglos institucionales que prevalecieron al instaurarse el modelo de desarrollo neoliberal y retomamos la noción de malestar social como un concepto que nos permite ubicar el malestar que pueden experimentar las abuelas cuidadoras frente a los conflictos vinculados al ejercicio de su abuelidad (Roo, Hamui y Fernández, 2017).

Las experiencias, así como la afectividad que está en juego en el desarrollo de la crianza, tienen en el enfoque cualitativo de investigación un recurso clave dado su énfasis naturalista e interpretativo (Vasilachis, 2006). En la sección destinada a la metodología presentamos las técnicas de identificación y selección de informantes, de obtención de datos y de su análisis.

\section{ANTECEDENTES SOBRE EL ESTUDIO DEL ENVEJECIMIENTO POBLACIONAL Y CUIDADOS DE NIÑAS Y NIÑOS}

El envejecimiento poblacional, como fenómeno demográfico, constituye el sustrato de múltiples procesos sociales actuales y configura sus formas futuras. Ello conduce a una atención generalizada respecto a las dificultades y los retos experimentados por las personas mayores a los 60 años, que en 2015 representaban 6.5 por ciento de la población y que seguramente se verán agravados en 2050, cuando esta población supere 20 por ciento (Téllez y Muradas, 2018; González K., 2015).

Uno de esos procesos, es la creciente interacción familiar en la que están involucrados parientes de generaciones previas a las de los padres, es decir, abuelos e incluso bisabuelos. Dicha convivencia, además de la consabida ampliación de la esperanza de vida, se propicia por la corresidencia con sus descendientes. Como muestra la Tabla 1, a nivel nacional, la población se concentra casi en 60 por ciento en hogares ${ }^{1}$ nucleares, prácticamente la

1 Por hogar nuclear, se entiende aquel que se compone de una pareja sola o un progenitor con alguna hija o hijo. El hogar ampliado se refiere a donde corresiden una pareja o progenitor con descendientes y otros familiares. Por su parte, el hogar compuesto es en el que cohabitan personas sin parentesco con personas emparentadas. Los hogares familiares son aquellos en los que los habitan personas emparentadas. Los hogares que son corresidencias no contienen a nadie emparentado, mientras que aquellos en los que sólo vive una persona, se identificaron como unipersonales. 
tercera parte de la población en hogares ampliados, mientras menos de tres por ciento reside en hogares unipersonales.

La población adulta mayor, por su parte, reside principalmente en hogares familiares aunque con diferencias notables por sexo. Alrededor de 40 por ciento de las mujeres reside en hogares nucleares frente a 50 por ciento de los varones, mientras que casi 46 por ciento de las mujeres y 37 por ciento de los hombres, habitaban en un hogar ampliado. Hay que notar que alrededor de 12 y de diez por ciento de mujeres y de hombres, respectivamente, no vivían con nadie.

Específicamente hablando del Estado de México, la distribución de la población por hogares es bastante parecida a la nacional concentrada en hogares nucleares y ampliados, mientras en los hogares unipersonales se nota una reducción de alrededor de dos por ciento para cada sexo. Es de señalarse que dicha reducción en la proporción de adultas y adultos mayores en hogares uniparentales tiene como contraparte el aumento de la proporción de los que residían en hogares nucleares.

Por otro lado, analizar la interacción entre generaciones, además de su incremento previsible dadas las tendencias demográficas, ha llamado la atención por los resultados benéficos para la familia y los menores que se han documentado. En Brasil y Perú, por ejemplo, la cotidianeidad compartida entre población adulta mayor y niños en edad escolar ha mostrado contribuir a la acumulación de capital humano y a la mejora de los cuidados de la salud de estos (Rentería, Maldonado y Lanza, 2007).

La etapa escolar ${ }^{2}$ es crucial para el desarrollo de los infantes, toda vez que es en ella cuando se tiene la oportunidad de afinar las competencias sociales facilitadas por los padres (Cuervo, 2010). Sin embargo, cada vez más, los padres destinan menos tiempo a la formación de sus hijos debido a la necesidad de procurarse los recursos necesarios para el sustento del hogar. Así, en los hogares donde es posible, la convivencia intergeneracional puede erigirse en un factor clave de cohesión social, al proporcionar a los menores la orientación necesaria aun en ausencia de los padres, lo que a su vez previene las desigualdades y discriminaciones por razones de edad (Delgado y Calero, 2017; Morfín y Sánchez, 2015).

2 La edad escolar comprende desde la segunda infancia (cinco años) hasta la preadolescencia (11 años). Cabe señalar que puede haber escolarización en edades previas o que el proceso de escolarización no concluye a los once años, estás referencias se utilizan para definir un rango en el que el desarrollo biológico es relativamente estable y consolida la experiencia de socialización en el aula. Las posteriores etapas de la vida suponen una serie de cambios biológicos y sociales con su propia especificidad (Woolridge, 2014). 
De la satisfacción al malestar social: abuelas cuidadoras de escolares en la Zona metropolitana ... / A. MARTÍNEZ y S.C. GAXIOLA

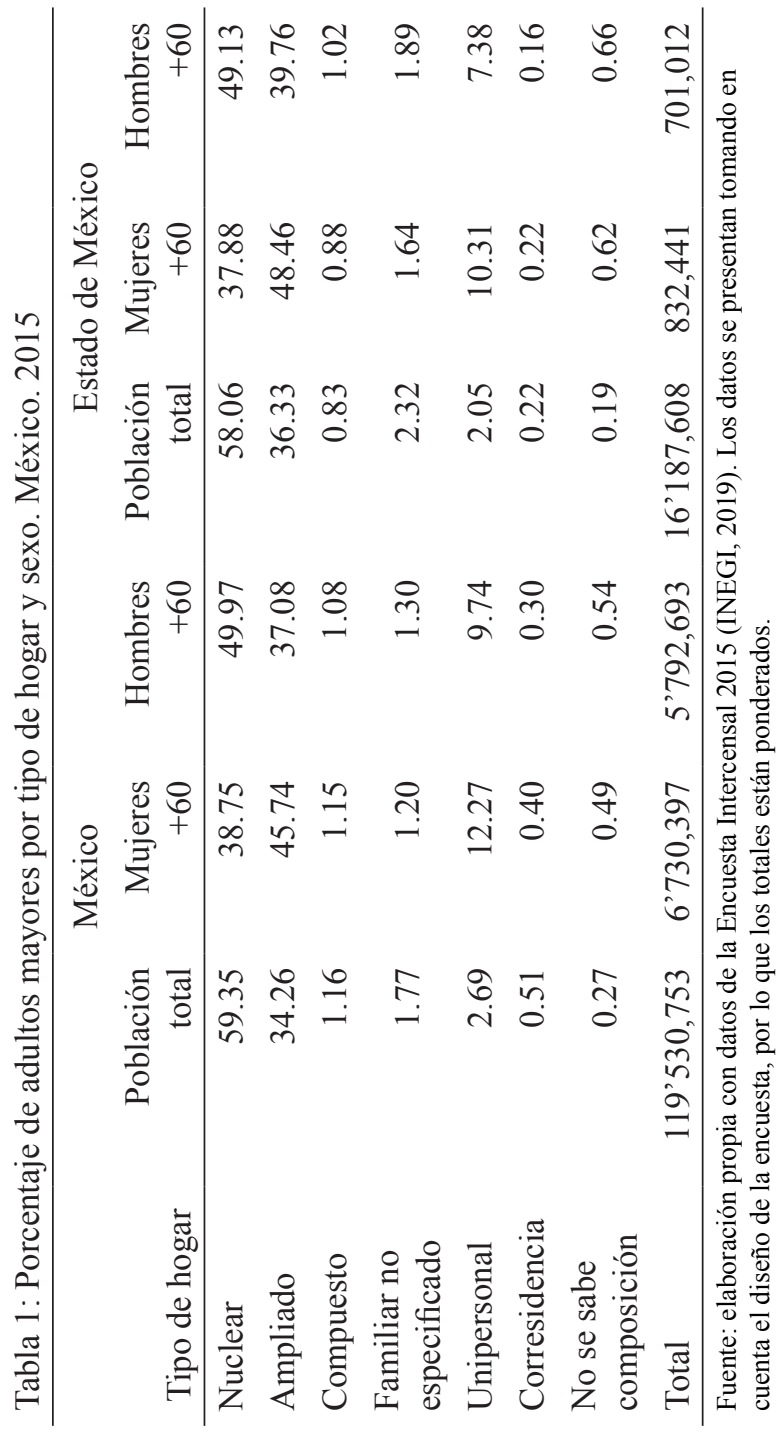


La Tabla 2 muestra el porcentaje de adultos mayores que cohabita con al menos una persona entre los cinco y los once años. Observamos como los adultos mayores que viven con población escolar, tanto en el país como en la entidad federativa, residen casi exclusivamente en hogares ampliados, es decir, con otros familiares además de los padres. Y aunque persistieron los adultos mayores que vivían en hogares nucleares, no llegan a dos por ciento en el caso de las adultas, mientras los varones apenas representaban nueve por ciento y ocho por ciento, a nivel nacional y estatal, respectivamente.

Tabla 2: Porcentaje de adultos mayores que cohabitan con escolares, por tipo de hogar y sexo. México. 2015

\begin{tabular}{lrrrr}
\hline & \multicolumn{2}{c}{ México } & \multicolumn{2}{c}{ Estado de México } \\
Tipo de hogar & Mujeres & Hombres & Mujeres & Hombres \\
\hline Nuclear & 1.47 & 9.00 & 1.43 & 7.7 \\
Ampliado & 94.20 & 86.62 & 94.35 & 87.93 \\
Compuesto & 1.44 & 1.39 & 0.83 & 1.02 \\
Familiar no especificado & 2.65 & 2.75 & 3.31 & 3.32 \\
Corresidencia & 0.08 & 0.04 & 0.03 & 0.02 \\
No se sabe composición & 0.17 & 0.19 & 0.05 & 0.02 \\
Total & 1 '134,467 & 968,010 & 154,112 & 130,547 \\
\hline
\end{tabular}

Fuente: elaboración propia con datos de la Encuesta Intercensal 2015 (INEGI, 2019). Los datos se presentan tomando en cuenta el diseño de la encuesta, por lo que los totales están ponderados.

La Tabla 2 también muestra que los adultos mayores que convivían con escolares, lo hacían en hogares familiares y escasamente cohabitando con otros no familiares. Esto define la crianza de la que serán objeto los menores, guiada por la obligación que suponen las redes de parentesco.

Ahora bien, los aspectos benéficos señalados antes son apenas una parte de la convivencia. En tanto que los roles de género son determinantes, hay que considerar que parte del trabajo del hogar, e incluso la responsabilidad por la educación y el cuidado de escolares, puede recaer en las mujeres y escasamente en los varones, llegando a considerarse como su obligación (Klein, 2015; Jiménez, 2011; 2012). Lo anterior no se opone a que el cuidado de niños y niñas, pueda ser profundamente gratificante, pues con ello evitan sentirse tristes o solas (Maldonado, 2015). Es pertinente señalar, también, que las mujeres mayores que cohabitan con menores suelen asumir el papel de abuelas, toda vez que en las familias contemporáneas, los 
vínculos obedecen a una definición que rebasa los vínculos de consanguineidad (Seltzer, 2019).

Al situar nuestra atención en los hogares intergeneracionales donde conviven adultas mayores y escolares, hay que reconocer la voluntad de ellas para atender a las niñas y niños, a pesar de que también pueden requerir diversos grados de cuidado. Esto contrasta notablemente con las líneas de investigación predominantes en la investigación de cuidados y envejecimiento, centrada en analizar a la población que experimenta los escenarios más adversos en los que la precariedad relacionada directamente con la pertenencia a los grupos de la tercera edad se combina con la presencia de algún padecimiento crónico (Flores, 2013). De modo que el énfasis puesto en la vejez como una etapa de dependencia y vulnerabilidad (Robles, 2005; 2006), puede restar atención a la comprensión de las contribuciones efectivas a la sociedad que realizan los adultos mayores; así como a las consecuencias de dichas contribuciones para quienes las realizan.

En ese mismo sentido, conviene situar la evidencia proveniente de los países de ingresos altos, al enfocarnos en las abuelas cuidadoras. En el contexto estadounidense, por ejemplo, la literatura suele caracterizar el cuidado de nietos como consecuencia de alguna problemática o crisis familiar como desempleo parental, abuso de drogas, embarazo adolescente, divorcio, padres en régimen de prisión, abuso infantil, violencia doméstica o problemas de salud mental o física (Klein, 2015). Puesto en estos términos, el cuidado que proporcionan las abuelas, es consecuencia de problemas sociales serios.

Ante ello, puede ser útil distinguir entre el cuidado custodial (incapacidad o falta de voluntad de los padres para proporcionar cuidado) y la corresidencia que puede ser una forma de procurar beneficios tanto para los cuidados como para los cuidadores y que se presenta de manera recurrente (Pebley y Rudkin, 1999). Del mismo modo, conviene considerar el carácter corresidencial o no corresidencial del cuidado, pues el primer tipo es poco frecuente (Luo et al., 2012). Finalmente hay que señalar que en los contextos económicos más favorecidos, las condiciones de salud de abuelos y abuelas, permiten que participen tanto en las labores del hogar como en la consejería y orientación de sus hijos adultos así como de sus nietos (Margolis y Wright, 2017).

En México, por su parte, la corresidencia entre múltiples generaciones que conduce a la modificación de la estructura y el tamaño de los hogares, ha sido una estrategia ampliamente seguida para optimizar los recursos, así como para hacer frente a las dificultades impuestas por el vaivén económi- 
co (Tuirán, 1993). En ese sentido, el cuidado y la significativa inversión de tiempo que supone, es uno de los recursos más valorables ante la creciente escasez de tiempo en los hogares (Damián, 2014).

Prestar atención a los hogares multigeneracionales adquiere toda su relevancia frente a las dinámicas de género prevalecientes respecto a la distribución del tiempo destinado a las labores domésticas y extradomésticas, así como el cambio en las estructuras de procuración del bienestar. A pesar de que se ha identificado una creciente participación masculina en las labores de cuidado, se presenta en mayor medida en los sectores más favorecidos, más jóvenes y urbanos (Pacheco y García, 2014; Rojas y Martínez, 2014; Martínez y Rojas, 2016). Asimismo, las estadísticas de uso del tiempo han dejado ver que, desde que se tiene registro, las mujeres siguen desempeñando las labores de casa aunque también tengan actividades laborales remuneradas (Santoyo y Pacheco, 2014; Rivero y Hernández, 2014; Rodríguez y García, 2014). Frente a una participación masculina insuficiente en las labores de cuidado y una escasez de tiempo de parte de las madres que trabajan con mayor frecuencia, la labor de las abuelas es crucial para el funcionamiento de hogares ampliados.

\section{LA PRODUCCIÓN DEL MALESTAR SOCIAL Y LOS CUIDADOS}

El otro aspecto que está fuertemente relacionado con la dinámica de los hogares multigeneracionales y la provisión de cuidados, tiene que ver con los arreglos institucionales desde los que el Estado, la familia y el mercado pueden atender las necesidades tanto de las generaciones nuevas como de las anteriores, teniendo siempre como referencia al modelo económico así como la evolución histórica de la sociedad (Welti, 2018). De modo que cada etapa de la vida supondría ciertos roles y la ocurrencia de eventos, como resultado del desarrollo económico alcanzado, lo que a su vez posibilita la inserción adecuada de los sujetos en la estructura social.

Durante la segunda mitad del siglo del siglo XX, México — como toda Latinoamérica- vivió un auge de modernización, sobre las bases de una intervención estatal orientada a la mejora de las condiciones de vida de las grandes mayorías con rezago alimentario, en salud, educación, empleo y seguridad social (Cortés, 2006; Enríquez, 2007). El esfuerzo del Estado, entonces, estaba orientado a combatir la marginalidad, e incorporar a la población al desarrollo, mediante políticas universales de abasto, salud y protección social. Lo anterior suponía una secuencia de eventos que al cumplirse, otorgaba la certeza de un futuro sin sobresaltos: atención médica y nutrición adecuada durante la infancia, acceso a la educación hasta 
la juventud, oportunidades laborales de acuerdo a la escolaridad, plan de seguridad social y retiro para los últimos años de la vida.

A finales de la década de los setenta, ya múltiples voces abogaban por una redefinición del rumbo del desarrollo económico hacia una "modernización del Estado" marcada por la privatización de paraestatales y la salida de áreas económicas clave (Andrea, 1992). Para esos críticos, el objetivo fue emprender un conjunto de reformas estructurales que reducían el tamaño del aparato gubernamental, así como sus ámbitos de injerencia (Kuntz, 2012; Grácida, 2004). A partir de las recomendaciones para el desempeño macroeconómico, los partidarios de la "modernización" del Estado, terminaron por generar un discurso que pugnaba por eliminar su papel en la redistribución del ingreso mediante servicios sociales. De modo que el gasto social, pasó de orientarse a compensar las consecuencias adversas de las crisis económicas a estar determinado por estas, no hubo más presupuesto para los servicios que no fueron privatizados y fueron transferidos a los estados, la capacidad ejecutiva de implementar políticas sociales se redujo, al tiempo que se enfatizó el uso de la familia y organismos de la sociedad civil, como promotores de bienestar social (Bustelo, 1991).

Para Bustelo (1991), esta desestructuración de la acción social del Estado, define al Estado de Malestar, que además de la dimensión institucional señalada, supone una dimensión psicosocial. Por un lado provoca desesperanza tanto por la reducción del ingreso y el desempleo, así como una restricción a empleos de baja calificación y bajos salarios, para la mayoría de la población. De manera paralela, infunde un descreimiento en la posibilidad de acceder a los servicios públicos, o se accede sólo a servicios deteriorados y sobrecargados (Bustelo, 1991: 221). Ese malestar fuertemente relacionado con las estructuras gubernamentales, genera experiencias de incertidumbre vinculadas a la soledad, la predominancia de lo privado frente al deterioro de la esfera pública, lo que permite una sobrecarga de responsabilidades individuales (Ramírez, 2012).

Ese escenario predominante desde la década de los ochenta, exhibe la desestructuración de la secuencia de eventos que conducía al bienestar y configura el otorgamiento de cuidados. En ese sentido hay que señalar la falta de consenso respecto a los últimos. Para las perspectivas más conservadoras, los cuidados tendrían que orientarse a permitir que los miembros del hogar obtengan un ingreso, que sean "productivos", sin considerar la calidad de la atención de los dependientes ni su impacto para quien cuida, lo que desatiende, además, la interacción entre estos extremos de la distribución etaria. Frente a ese sesgo productivista, las visiones críticas ponen 
el acento en la contribución al desarrollo y el mantenimiento del tejido social que se produce en los hogares que permiten el intercambio de afectos, saberes y prácticas de generación en generación (Flores, 2013).

Es así que nuestro interés está situado en las experiencias de las abuelas respecto a los cuidados que proporcionan a escolares, ampliando la visión que suele considerarlas sólo como receptoras de cuidado. A partir de ello, explorar las ambivalencias que envuelven a la convivencia intergeneracional, problematizando la visión utilitaria y productivista que puede acompañar al análisis de los cuidados.

\section{Materiales y MÉtodo}

Para llevar a cabo el propósito señalado, se analizó de forma cualitativa un conjunto de nueve entrevistas en profundidad, realizadas como parte del proyecto de investigación "Representaciones y consumos alimentarios de las poblaciones en edades escolares y en edades avanzadas del Estado de México". Dentro de dicha investigación, las unidades de observación fueron adultas mayores que convivían con niñas y/o niños en edad escolar (entre cinco y once años). Las entrevistas estaban orientadas a dar cuenta de la organización de las actividades domésticas y las formas de relacionarse, en conexión con las percepciones que se elaboraban sobre los alimentos.

Para conformar la base de datos de participantes en el estudio, se empleó la técnica de búsqueda y selección de informantes de "bola de nieve" (Martínez, 2012), es decir, que una persona puede proporcionar información para este estudio y a su vez, indicar quienes más cumplen las condiciones de selección y podrían estar interesadas en responder a la entrevista, pero ajustándose siempre al cumplimiento de variabilidad en cuanto al tipo de hogar, para seleccionar a las participantes.

Aunque la muestra estuvo orientada a captar otra serie de procesos, las narraciones de las mujeres participantes aportaron elementos valiosos para explorar las experiencias de cuidado intergeneracional en diversos hogares. Dicha exploración no supone la aspiración de constituir un análisis representativo de las diferentes experiencias posibles de cada tipo de hogar, en su lugar, buscamos ilustrar en la concreción y especificidad de lo vivido por cada mujer, las implicaciones de ser abuelas cuidadoras en una época en la que se privilegia la vulnerabilidad individual más que los derechos sociales. De modo que el análisis estuvo orientado a los casos en los que la intensidad de los diferentes fenómenos fuera mayor (Martínez, 2012), sin que se afirme su ausencia en el resto de los casos. 
En el mismo sentido, la referencia a la Zona Metropolitana de Toluca enmarca el contexto en el que dichas experiencias son posibles como elemento necesario para la interpretación cualitativa (Vasilachis, 2006), más que para la representatividad de los hallazgos.

Aunque en la muestra se observó que las participantes provenían de diferentes tipos de hogares, en su mayoría residían en hogares ampliados. Cabe señalar que al momento de "hacer rodar" la bola de nieve, fueron contactadas mujeres que cuidaban de escolares y que estaban dispuestas a conversar con los investigadores, pero no cohabitaban con los menores. Se tomó la decisión de integrar sus testimonios al estudio, en tanto que esa situación nos podría aportar variabilidad y enriquecer el análisis. De ese modo, se entrevistaron a abuelas en hogares nucleares e incluso una en hogar unipersonal. La base final se conformó de nueve entrevistas, cuyas características se presentan en la Tabla 3.

Las entrevistas fueron realizadas entre noviembre de 2018 y enero de 2019. Para asegurar la libre participación en el estudio, todas las participantes estuvieron de acuerdo con el documento en el que se respalda su consentimiento informado. Dicho documento fue leído y firmado por ellas mismas, o se les leyó cuando fue necesario. En él también se describían las características de la investigación, el uso que se le daría a las grabaciones, así como la condición de no contestar lo que no quisieran o interrumpir la entrevista si lo consideraban necesario. Los nombres utilizados para dar a conocer los hallazgos derivados de las entrevistas, han sido cambiados para proteger la privacidad de las mujeres entrevistadas.

La exploración de las experiencias de las abuelas cuidadoras se realizó a partir de sus narrativas, mediante un análisis cualitativo exploratorio recuperando algunos elementos del microanálisis, técnica de análisis que se apoya en el examen e interpretación línea por línea de cada una de las entrevistas, comparando y formulando preguntas constantemente (Strauss y Corbin, 2002). La herramienta fundamental del microanálisis es la codificación, que procede en etapas más o menos secuenciales. La codificación abierta nos permitió generar una serie de "etiquetas" para identificar las experiencias de nuestras informantes en torno a su condición de abuelas. A partir de ello, mediante la codificación axial se organizaron dichas experiencias a partir de su intensidad, identificando cinco experiencias: las abuelas como cuidadoras principales, como auxiliares, con impedimentos para proporcionar los cuidados esperados, independientes de sus descendientes y aquellas que enfrentaron tensiones inconfesables en esa interacción intergeneracional. 


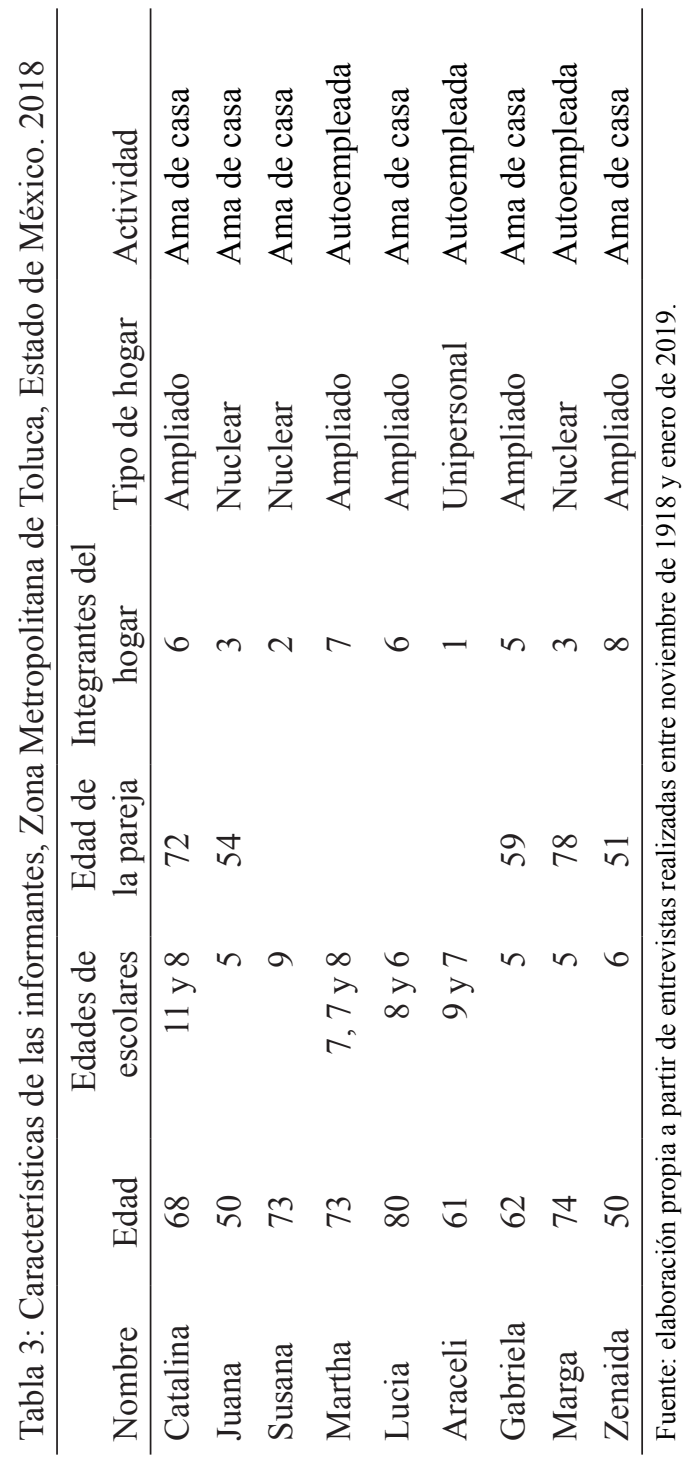


Por su parte, la codificación selectiva se empleó para seleccionar aspectos o matices que ayudaran a clarificar el sentido atribuido a las interacciones con las y los escolares, definidas en la codificación axial.

Cabe señalar que como se dijo antes, aquí se exploran aspectos vinculados a las relaciones intergeneracionales. En otra publicación se pueden hallar algunos elementos analítico-conceptuales que se centran en las prácticas alimentarias, objetivo del estudio para el que fue seleccionada la muestra originalmente, buscando aportar elementos para la definición de políticas públicas enfocadas a promover la mejora en este aspecto a nivel poblacional (Lozano, Martínez y Montoya, 2019).

\section{RESULTADOS: EXPERIENCIAS DE ABUELIDAD}

Un primer aspecto que se identificó en las mujeres entrevistadas fue que en todos los casos los escolares cohabitaron con varios familiares, es decir, ninguno estuvo bajo la tutela exclusiva de la abuela; sin embargo, en los casos de las señoras Juana, Marga y Zenaida, ocurrió que ellas eran quien se encargada del cuidado de nietas y nietos la mayor parte del día.

Doña Juana vive junto a su pareja y el menor de sus dos hijos de 18 años, quien ya realiza buena parte de sus actividades de forma independiente, de modo que más allá de la alimentación son pocas las actividades que realiza por él. Su hijo el mayor tiene 28 años y ha formado su propio hogar en el que ambos tienen un empleo remunerado, por lo que recurren a ella para que cuide a su nieto prácticamente todo el día:

Nosotros nos encargamos de bañarlo todos los días. Porque su mamá nomás pasa le da su vaso de leche, se lo toma y ya, luego más al rato que ya pide de almorzar y ya almuerza (..) ya cuando sale tarde del trabajo y no le da tiempo de ponerle lunch me dice y ya veo que le preparo (Doña Juana, 50 años, unida, hogar nuclear).

Llama la atención como se refiere a que ellos se hacen cargo del niño. En realidad, el hijo de doña Juana se ocupa en actividades con los amigos, las redes sociales y la universidad, su esposo llega por la tarde-noche para apenas jugar con su nieto. Para la noche el niño limpio y alimentado puede volver con sus padres cuyas jornadas largas les impiden tener la energía para convivir todavía con él. El hecho de que todo el día lo pase el niño con su abuela, no representa ninguna dificultad

a mí se me hace fácil (cuidar al niño), porque en si no ha sido un niños problemático, desde chiquito lo sentaba para darle de comer y él decía 'yo', y se 
sentaba y comía (...) y pues si nos decían que lo mandáramos al kínder pero como que no... y aparte como es el primero, no se nos ha hecho tan difícil ni pesado. (Doña Juana, 50 años, unida, hogar nuclear).

La condición de abuela joven de la señora Juana, nos permite entender su oposición despreocupada porque su primer nieto vaya a la escuela.

La señora Marga, a sus 74 años, cohabita con su pareja y la más joven de sus hijas. Aunque su esposo ya está retirado, al igual que ella, no aparece en las narrativas del trabajo doméstico o de los cuidados de su nieta de cinco años de edad o del nieto de nueve. Ella refirió que se hace cargo de la limpieza de su casa de tres plantas, lugar preferido de juego para sus nietos, identificando una serie de dificultades:

(...) A mí me toca el aseo, me toca lo más duro, con los chiquillos, dejan el triciclo en un lado la bicicleta en otro lado, ¡no, no, no! es una cosa que luego me dice mi hija 'oye mamá pero este juguete de mi hijo...' 'mijita levántalo, yo ya me canse, yo ya no...' (...) en cuanto a las labores domésticas nunca me ha gusta que me ayude nadie, ni a ropa ni a nada, nada, nada, lo que pueda yo hacer y hasta donde pueda. Me cuesta mucho trabajo subir las escaleras y estar bajando pero las bajo al revés, ji ji ji ji, y subo con trabajos pero subo, es que es bien difícil la cuestión de las personas que ayudan. (Doña Marga, 74 años, unida, hogar nuclear).

Sin embargo, al referirse al cuidado que provee a sus nietos, es notoria la disociación que hace de la carga de trabajo que ello representa y que resalta en la narración previa,

Me parecen mmm..., fáciles (los cuidados para sus nietos) pero de mucha responsabilidad, es mucha responsabilidad tanto a la niña como al niño (...) porqué a él (a su pareja) el estilo norteño no se le quita, híjole es que dicen muchas cosas que no deben ser para mí (...) algunas palabras que decimos groserías (...) yo siempre le he dicho al niño, y el niño hasta la fecha no dice ni una grosería, y su hermanita, 'no hay necesidad de que digas lo que dice tu abuelo', en fin (...) en los hombres a lo mejor, pero las muchachas ahora son tan común, ahora yo escucho a las chiquillas que vienen de la secundaria que ¡Diosito Santo, no puede ser! que hablen los escuincles enfrente de las chamacas vulgaridades y las chiquillas risa y risa como celebrándoles, en ese sentido es lo único que se me hace muy difícil (...) yo siento que es muy seria por la educación, los principios, los valores (Doña Marga, 74 años, unida, hogar nuclear). 
Doña Marga resalta la importancia de la crianza, como una forma de inculcar valores, lo que representa una tarea más ardua que levantar y limpiar la casa.

El otro caso en el que identificamos que los nietos pasaban más tiempo con las abuelas que con sus padres, fue el de Doña Zenaida, aunque ella si corresidía con sus descendientes. Al unirse cambio su domicilio a la casa de su pareja, ubicada en una de las calles principales de la colonia. Aprovechando eso, pusieron un negocio de venta de frutas y verduras que fue muy exitoso durante varios años. Con los ingresos obtenidos pudieron construir su casa y ampliarla para cuando les tocara el turno a sus hijos de formar su propia familia. Así, el mayor de 28 años se ha unido y ha procreado a dos niñas de tres y cuatro años y a un varón de seis. La labor de crianza aún no ha terminado para doña Zenaida puesto que su hija de 16 años cursa la preparatoria y requiere aun de su apoyo. Claridosa, como la caracterizan las personas que la conocen, habló de las dificultades que enfrenta al hacerse cargo de sus nietos:

Antes los hijos [...] les echaba un grito y se calmaban, se estaban quietos, y ahora ya no. Ahora los niños dicen, ‘¿Ay, por qué?', pero pues también hay que enseñarlos a que mientras están con uno y no está la mama, está trabajando, pues tiene uno la autoridad con ellos y yo si les digo cuando no me obedecen, 'Ah bueno, como no me obedecen, no me hacen caso ahorita que quieran comer, no me pidan, porque no estoy yo, hasta que llegue su mamá que les dé de comer y ustedes le piden a ella, porque no es mi obligación es de tu mamá yo le ayudo, pero si no quieren no', y ya después me dicen, 'Abue, bueno', ya como que le bajan tantito (Doña Zenaida, 50 años, unida, hogar ampliado).

En ese proceso de lidiar con la falta de obediencia de los niños, Doña Zenaida ha tenido diferentes tensiones con su nuera, lo que la ha llevado a dejar las cosas muy claras con ella, sobre todo ante su situación laboral:

A veces, desgraciadamente la mujer cuando se va a trabajar se desentiende de los hijos totalmente y pus yo lo veo así como que pues se quedan... 'me da lo mismo, si se portan bien pues también, y ella no ve lo que está mal o no, lo que los niños hacen o no, 'Mamá, vamos a hacer la tarea, ¿me ayudas, me apoyas?' (...) todo es malo, los apoya uno es malo y no los apoya uno es malo porque les quita mucho la autoridad, y mucha responsabilidad que ya no nos corresponde a nosotros, yo los apoyo porque no me gustaría que los niños crecieran como puedan, pero pues tampoco es mi obligación y ya le dije a ella 'sabes que, ahora si piensa como hacerle, porque ya la otra ya va a entrar al Kínder, piénsale y siéntate con tus hijos porque yo la verdad, yo la responsabilidad mía es mi hija nada más, me corresponde ir a dejarla, ir a traerla, estar al pendiente de 
ella, de todo, tus hijos no, te apoyo, una cosa es apoyarte y otra cosa que es responsabilidad para mí', según que ya va a dejar de trabajar, pues espero, porque van creciendo y los niños entre más crecen es imposible ahorita ya educarlos, la verdad, ¡Esta muy difícil!, los niños están muy despiertos, ya no quieren ni que les grite uno, ni que les llame uno la atención porque se vuelven..., ya no, se salen de control y pues no es los mismo que uno los eduque, que uno les llame la atención, para mi está mal que trabaje una mujer pero pues... yo nunca lo hice, nunca los deje para que también crecieran bien... (Doña Zenaida, 50 años, unida, hogar ampliado).

Ese proceso de invertir tiempo en la formación de escolares, se puede ver atravesado por las diferentes circunstancias en las que los padres de sus nietos estén llevando su relación. De modo que como en los casos anteriores, ellos pueden ser parejas que recurren al apoyo de las abuelas para generar mayores ingresos. Pero también es posible que la pareja haya decidido separarse y mantener el cumplimiento de sus obligaciones. Este es el caso del nieto de la señora Gabriela, al no funcionar las cosas entre su hija y su pareja optaron por separarse, de modo que uno de los acuerdos es que su nieto debe de pasar una semana con su padre y una semana con su madre, situación en la que fue importante la participación de los abuelos maternos,

Cuando ella se separó de su marido, le dije 'vente, ni modo que te vayas a rentar' entonces vino y un rato trabajó, lo dejaba arreglado o yo lo arreglaba y lo iba a dejar y como (su papá) al principio no iba a trabajar, él le decía yo voy y ya se encargaba y sigue ahorita, (si su hija) se va a trabajar, sale o cualquier cosa, yo lo cuido.

Él (su ex-yerno) dijo que no le quería dar pensión y mi esposo le dijo 'No, tú le vas a dar porque están casados' y aunque no estuvieran su obligación es darle al niño y sí, creo que le quedó de dar [pensión] ella metió licenciado y para él antes trabajaba en gobierno y de ahí le descontaron, y le llegaba sin meterse con nadie, pero el entonces renunció a sus trabajo y ya luego el viene, el viene y le deja dinero al niño (...) Mi esposo habló con él y pues hasta ahorita han vivido bien, no hemos tenido problemas. (Doña Gabriela, 62 años, unida, hogar ampliado).

Ese tipo de acuerdos permite que atender al niño sea una experiencia gratificante, tanto porque ayuda a su hija al llevarlo y traerlo de la escuela como porque le sirve también para caminar. Además, la posibilidad de que dos familias estén pendientes de su nieto aminora de cierta forma la carga 
de trabajo que pudiera significar. Sin embargo, ello ha requerido afrontar también tensiones en cuanto a los vínculos afectivos hacia ambos padres,

Es un niño muy educado, y aquí le digo que lo queremos mucho pero su papá, ufff, su papá ha de ser mujeriego pero es un papá muy responsable, quiere más a su papá que a su mamá jajajaja si con eso le digo todo (...)

Ya ahorita está calmado (su nieto), pero antes a todas horas estaba juy con sus groseríasi, no se quería bajar del carro, no se quería venir... luego lo traía y pues no se quería bajar, se quería quedar con sus papá y ya poco a poco como que ya fue creciendo y yo creo, pues quien sabe allá como lo trataban y ahorita ya está bien tranquilo, ayer vino a dejarle unas cosas que le pidió de la escuela, sale, lo saluda y se vuelve a meter, así ya bien tranquilo. (Doña Gabriela, 62 años, unida, hogar ampliado).

El compartir la vida con ambas familias enfrenta a la señora Gabriela con la incomodidad de la separación e implícitamente a una disputa simbólica entre los padres por el afecto del niño, lo que repercutía, en forma indirecta, en su percepción de la asignación de afecto hacia toda la familia.

Otra forma de relación que identificamos se caracterizó por un apoyo auxiliar, aunque cohabitaban la abuela y los nietos. Doña Martha había formado su familia a los 26 años, su pareja la maltrataba de diversas maneras por lo que optó por criar a sus hijos sola, buscando el apoyo de sus padres. A fuerza de trabajar, logró hacerse de un patrimonio, mismo que ya repartió entre sus hijos. La más joven se embarazó mientras cursaba la preparatoria, y aunque vivió con el padre de su hija, regresó a vivir con su madre, por lo que la niña ha crecido con su abuela. Eventualmente, doña Martha se encarga de alimentar o recoger a la niña de la escuela, opciones que le da el tener su negocio propio, pero su hija es la principal responsable. También vive con ella un hijo. Hace unos meses su casa se quemó por lo que busco también su apoyo, en su trabajo solicitó el horario nocturno para poder atender a sus hijos, dado que su esposa ya no vivía con ellos. Si bien cada quien se ocupa de sus hijos, Doña Martha ha tomado a su cargo la preparación de alimentos para todos, lo cual no excluye que si algo se les antoja puedan llevarlo y ahorrarle ese trabajo. Doña Martha se percibe sana, de lo único que se queja es del cansancio. A pregunta expresa sobre su propia necesidad de cuidados, ella, sin rasgos de queja pero con ánimo pesimista, narró,

Pues, ¿a quién se los pido? (los cuidados), ¿quién me los daría?, de ahí es de lo que a veces les hecho relajo a mis hijos, les digo, 'oigan, yo ya voy a cumplir 72 años’ y yo en relajo les digo, '¿cuándo creen que me van a jubilar?', luego 
les ando echando relajo, les digo, 'ustedes ya deberían ponerse de acuerdo para jubilarme, pues entonces cuándo', usted cree que luego a veces me pongo a pensar, pues cierro el negocio, lo cierro, pero créame que con lo que he visto quién cree que me dé un centavito, ¿de qué me la voy a vivir, de qué voy a pasar mi vejez más adelante, de qué?, si yo vi con mi papá que a pesar de que les dio y todo y quién dijo padre ten, ¿qué me espera?, imagínese (Doña Martha, 72 años, separada, hogar ampliado).

El caso de Doña Susana ilustra situación en la que el contacto nietos-abuela es más bien esporádico y no precisamente para prestar cuidados a los nietos, con ello muestra los limites en los que se puede proporcionar los cuidados. Doña Susana nació y creció en su domicilio. Con 73 años se hace cargo de sí misma, vive con uno de sus hijos y cada semana es visitada por alguno de sus nietos, en sus palabras:

Ya, ahorita ya no (puede cuidar), más antes si me llegaba a quedar yo con uno, pero así casi no siempre sus mamás se han hecho cargo de ellos, nada más le cuide a uno de sus hijos a mi hija pero vive más arriba y antes estaba aquí, entonces yo, yo lo vi (...) cuando estaba yo más joven no me costaba tanto trabajo pero ahorita si ya no me, no fácilmente me hago responsable de los nietos. (...) puede pasarle alguna cosa o algo entonces ya, ya mejor ya cada quien se hace este, responsable de, de los de sus hijos (...) sufro de hiper... soy hipertensa, tengo diabetis, el cisticerco en la cabeza y pues ya, ya no estoy ahora si como para ver a los nietos, porque pus es difícil, a veces dan lata, se vayan a caer, les vaya a pasar algo, ellos también ya saben y no me los dejan, ya no me los dejan por ese motivo (Doña Susana, 73 años, viuda, hogar ampliado).

Sin embargo, el cuidado que todavía proporciona es la alimentación, sus nietos que la visitan aún tiene la oportunidad de sentarse a la mesa a esperar que su abuela les sirva los alimentos preparados con las recetas que las vida moderna se ha encargado de ir borrando.

Doña Catalina muestra otro caso notorio por la cercanía que representa con sus nietos, al habitar en una casa contigua a la suya en un terreno familiar, y sin embargo, tener una dinámica independiente a la de sus nietos. Aunque cohabitan en el mismo terreno, pocas veces algunas de sus nueras recurre a buscarla para pedirle apoyo. Más allá de la comida que prepara para sus hijos solteros que viven con ella y que eventualmente puede compartir con alguno de sus nietos, ella interviene poco en su cuidado. Dicha actividad no le resulta difícil porque según ella misma dice "no tengo otra cosa que hacer", tampoco considera que ella necesite cuidado. 
El cuidado de las nietas y nietos, puede estar cargada de tensiones que difícilmente perceptibles, incluso para los padres. Estas tensiones se relacionan con las expectativas que asumen que tienen sus familiares. La señora Araceli vive sola, sus tres hijos han hecho su vida aparte. A veces entre semana pueden llegar sus nietas, pero los fines de semana su casa es un lugar de encuentro para ellas. Esto aunque estaría revestido de un sentido positivo, de mostrar y recibir afecto, es en realidad motivo de tensiones inconfesables a las que las abuelas se exponen en su vida diaria.

Me desespero por la cuestión de que parece que ellas hablan otro idioma, incluso la niña chiquita de siete años que la liga, que no sé qué de los teléfonos, no les manifiesto que me desespero, obviamente soy muy paciente pero interiormente digo '¿pero de qué me están hablando, no?' Me siento obsoleta en ese sentido, no me gusta porque mi vida se desarrolló, mis actividades se desarrollaron muy arcaicamente, hacer de comer y no meterme un poquito más en la innovación de ahora, ¿no?, tanta cuestión de internet, y todas estas cosas y si me desespera porque aparte tienen otras costumbres ya, aunque mis hijos fueros educados por mí, bueno porque su papá murió hace muchos años (...) yo les dediqué el tiempo que... (sollozos)... que podía, yo siempre les di tiempo de calidad (...). El decir que me desesperan mis nietos es porque si los disfruto y todo eso, sí, sí, sí, pero yo tengo, yo quiero otro tipo de vida o sea, tener paz, me gusta mucho la soledad convivo mucho con ella, o a lo mejor eso es lo que me falta, convivir con más gente ehhh, no soy muy abierta, me guardo muchas cosas (Doña Araceli, 61 años, viuda, hogar unipersonal).

A pesar de disfrutar las visitas de sus nietas, la señora Araceli apunta que también hay un sentimiento de frustración debido a la falta de comprensión de lo que es importante para la vida de ellas. Otra tensión que está presente en la necesidad de paz, de preferir convivir con la soledad. Estas tensiones, al parecer, se sustenta en la forma en la que se dio la crianza de sus hijos, la idea latente de que el tiempo que les dedicó pudo haber sido insuficiente. Un último aspecto clave es la dificultad para comunicar un sentimiento que no cabe en las convenciones sobre los afectos abuela-nietas.

Finalmente el testimonio de la señora Lucia nos muestra la tensión de tener una vida satisfactoria, con muchas dificultades al principio pero que en estos días le da la posibilidad de recuperar las experiencias de sus hijos con orgullo, a la par de desear que llegue el fin de sus días.

Mi niñez fue triste, pero, pero ya de casada y mis hijos, son una maravilla de hijos que tengo. (...) Me cuidan, me ayudan, me socorren, me llevan al médico, les digo ya no me lleven hijos, ya no gasten su dinero. (...) Porque la verdad, la verdad, sinceramente ya no... ya no quiero vivir, ¿para qué? Pero bueno 
mientras mis hijos le echen ganas, voy a echarle ganas yo también (Doña Lucia, 80 años, viuda, hogar ampliado.)

Después de criar a nueve hijos y llegar a tener once biznietos, sus recuerdos se envuelven en una atmosfera de orgullo, ya está cansada, extraña profundamente su matrimonio que fue pura dulzura para ella, con todo aún puede a sus ochenta años recolectar leña para hacer tortillas y atender todavía a dos de sus biznietos. ¿Cómo negarse a seguir viviendo si sus hijos, sus nietos y sus biznietos se esfuerzan por ello?

\section{Discusión y CONCLUSIÓN}

En las sociedades modernas en las que el Estado ha jugado un papel importante en la protección de las personas adultas mayores, parece prevalecer la idea de que esa población se encuentra cada vez más, ya sea en instituciones o en sus domicilios, viviendo en desiertos de soledad, marcados por el aislamiento emocional (Elias, 1989). En México, se observa que si bien alrededor de diez por ciento de las mujeres mayores a 60 años residen en hogares unipersonales, también es cierto que las abuelas viven en hogares familiares, y prácticamente todas las que conviven con escolares residen en hogares ampliados. Incluso en hogares unipersonales, como se pudo mostrar, es posible que exista convivencia intergeneracional.

A partir de las narraciones de las participantes, se identificaron experiencias de abuelas que colaboraban de alguna forma a cuidar a los nietos y todavía más, en el caso de doña Juana, quien consideraba que aún no era conveniente enviar a su nieto a la escuela y que ella podía seguir cuidándolo la mayor parte del día. En contraparte, doña Susana refería una serie de malestares que la hacían sentir imposibilitada para atender a sus nietos, aunque la preparación de alimentos es una labor que aun atiende cuando la visitan. Ahora bien, identificar que la vida de las personas adultas mayores escasamente se da en escenarios de soledad, no quiere decir que se sostenga de forma armónica.

Las mujeres entrevistadas enfrentaban múltiples malestares que aunque se expresaban en aspectos físicos o emocionales no pueden dejar de ubicarse en un contexto social más amplio. La pérdida de habilidades que conlleva el proceso de envejecimiento, puede conducir a suponer también, una paulatina disminución de la capacidad e incluso del derecho a tomar decisiones, en la medida en que la persona se vuelve más dependiente (Flores, 2013). Esa desubjetivación está implícita en diversos grados en la prestación de cuidados de las abuelas. Para doña Araceli, esa incapacidad 
de decidir se manifiesta en la frustración por no poder confesar que se desespera por no entender el mundo de sus nietas, a la par de la perturbación que siente de la tranquilidad de su hogar. El supuesto de que las abuelas deben de valorar positivamente las visitas de los nietos y demostrarles amor (Maldonado, 2015), provoca en ella una tensión muy fuerte por lo que prefiere guardar su desesperación para no lastimar a su familia. Más allá de un problema individual, la experiencia de la señora Araceli muestra la desatención que tiene la promoción de las tecnologías de la información entre las personas de la tercera edad. Este aspecto no es menor en tanto que les permiten aumentar y mejorar su desarrollo individual y social. La literatura al respecto, muestra que esos aprendizajes pueden reforzar la autonomía y la autoestima. Acceder a las Tecnologías de la Información da paso a que el adulto mayor se mantenga informado y con ello, integrado al mundo actual, pero sobre todo, a vencer el miedo a la soledad y al aislamiento (Ortiz, 2007; Rodríguez, 2007). Cabe señalar que en Argentina ya se han impulsado programas de esta naturaleza con resultados alentadores (Frávega et al., 2008).

Por otro lado, la disputa simbólica por el afecto del nieto, que se identificó en el hogar de la señora Gabriela, estuvo acompañada por la intervención de otros actores menos enfocados en la interpretación de lo que estaba ocurriendo y más enfocados en lo debería de ocurrir. En México existen fuertes limitaciones en los mecanismos para asegurar el pago de la pensión alimentaria (Benítez, 2012), lo que llevó a la intervención de un abogado y antes del abuelo. Tanto por los honorarios del litigante como por el cuidado y el apoyo emocional, la separación representó un costo para los abuelos, aunque dado el desarrollo de la situación ha resultado una inversión. Esa disposición a cubrir las necesidades de sus hijos, en la medida de sus posibilidades, llevó a que la familia de nuestras informantes buscara suplir labores que el Estado debería proveer. Recordemos que el hijo mayor de doña Zenaida vive con ella, y es la razón de discusiones con su nuera al estar encargada de labores que le corresponden a esta. Es de notar que la principal forma en la que nuestras informantes ayudaron a sus hijas e hijos ha sido abriéndoles su casa, esto adquiere todo su valor al considerar que, poblacionalmente, si los adultos mayores en contextos urbanos, tienen la propiedad de su vivienda presentan menor probabilidad de cohabitar con sus hijos (Ybáñez, Vargas y Torres, 2005). Es decir, los recursos de los adultos mayores, en tanto parte de familias extensas y ampliadas, han sido decisivos para enfrentar las dificultades, de sus descendientes de nuestros 
informantes y ello debe ser considerado en las políticas que buscan atenderlos.

Uno de los motivos de preocupación explícitos que compartían doña Zenaida y doña Marga, sobre el cuidado de sus nietos, era el de su formación. El cansancio y las molestias en las rodillas de doña Marga se opacan ante las dificultades que percibía por formar a sus nietos, de inculcarles los valores que ella apreciaba. Desafortunadamente, a diferencia de la señora Zenaida ella si consideraba propia esa labor. Es ese protagonismo el que ha conducido a que su hija reclame de ella cierta obligatoriedad en la atención de su hijo, lo que a ella le permite ser indulgente, compensando el escaso tiempo que tiene disponible para su hijo. La obligatoriedad en el cuidado que se observa en el papel de la abuela, contrasta notablemente con la poca consideración que se le presta al tiempo de trabajo de las mujeres mayores (Damían, 2014).

El apoyo económico que recibe doña Marga puede ser el elemento que le permite volcarse en la atención a sus nietos, reforzando esa obligatoriedad. En el caso de la señora Martha, esa necesidad de transferencias monetarias no deja de estar presente, aunque sólo se permite expresarlas a sus hijos como echando relajo. La desesperanza por su sobrevivencia en el futuro hacia que doña Martha no pensara en dejar de trabajar a pesar de su cansancio, tomando como referencia los últimos años de su padre. Sin una pensión o siquiera la expectativa de que sus hijos la apoyen, su trabajo es lo único que le da algo de certeza. Ella es una muestra de las

soluciones fragmentadas, descoordinadas, incompletas e inconsistentes a un problema creciente a la luz del envejecimiento de la población y de la incapacidad del sistema de seguridad social de garantizar un ingreso a los individuos al final de su vida productiva (Rubio y Garfias, 2010: 41).

La participante de mayor edad, doña Lucia, superó los setenta años cuando se amplió la cobertura de los apoyos a los adultos mayores, en la pasada década; sin embargo, señala que ese apoyo no le alcanza. Múltiples padecimientos que no la detienen, requieren de gastos importantes que no son cubiertos por el sector salud. Es frecuente que sus hijos la lleven a consulta con especialistas privados cooperándose. La señora Lucia se hace fuerte, recolecta leña, cocina para sus biznietos, limpia su casa. Agradece a la vida por sus hijos, al tiempo que señala su voluntad de morir. Le preocupa que gasten tanto sus hijos y extraña a su fallecido esposo. En México, sigue siendo un tabú hablar de las decisiones al final de la vida. Hace falta mucho todavía para tratar el tema de forma socialmente aceptable y toda- 
vía más para proporcionar los programas de salud que permitan apoyar a las personas que hayan decidido establecer el fin de sus días. Esto supone desde los cuidados paliativos más básicos, hasta la consideración legal de la muerte con asistencia médica, cuyo acompañamiento no esté sujeto a las instituciones hospitalarias puesto que la mitad de casos ocurren en los domicilios (González E., 2015).

De manera amplia, se puede señalar que existen múltiples matices en la convivencia intergeneracional, que difícilmente se ajustan a las expectativas atribuidas al rol de abuela (disposición al cuidado, valoración positiva de la relación con la descendencia, etc.). Es frente a esas expectativas que diversos malestares pueden aparecer como mencionamos antes; sin embargo, sería erróneo asumir que dichas expectativas son una característica personal disfuncional de los familiares con los que conviven. En realidad, tendríamos que considerar los criterios de la abuelidad culturalmente establecidos y buscar una definición que sea consistente con el objetivo de promover el bienestar en toda la población. Por supuesto que ello requeriría el desarrollo y la recuperación de un andamiaje institucional debilitado y frágil, después de décadas de abandono, o como se suele presentar en la literatura especializada, es necesario recuperar políticas integrales (Yanes, 2011).

Finalmente, es pertinente señalar que las nietas y nietos fueron llevados o crecieron en la casa de los abuelos, es decir, el cuidado no tuvo como escenario la independencia de los hijos. En los casos analizados, los hijos no reciban a su madre para ayudarla y ella contribuía con el cuidado de las nietas y nietos. Se trató de madres que recibieron en sus domicilios a sus nietos e incluso a la familia completa, ellas fueron quienes apoyaron a sus familias. Este es un rasgo en el que conviene profundizar en todas sus implicaciones en posteriores estudios.

\section{REFERENCIAS BIBLIOGRÁFICAS}

Andrea, F., 1992, "La modernización del Estado mexicano: reforma económica, política y educativa", en Boletín Mexicano de Derecho Comparado 1(74). doi:http://dx.doi.org/10.22201/iij.24484873e.1992.74.2954

Benítez, M., 2012, "Incumplimiento de pago de pensiones alimenticias a jefas de familia en Mazatlán Sinaloa", en Contribuciones a las ciencias sociales, (201202).

Bustelo, E., 1991, "La producción del estado de malestar. Ajuste y política social en América Latina”, en Salud Pública de México, 33 (3), 215-226. 
Cortés, F., 2006, “Consideraciones sobre la marginación, la marginalidad, marginalidad económica y exclusión social”, en Papeles de población, 12(47), 71-84.

Cuervo, Á., 2010, "Pautas de crianza y desarrollo socioafectivo en la infancia", en Diversitas: Perspectivas en Psicología, 6 (1), 111-121.

Damián, A., 2014, El tiempo, la dimensión olvidada en los estudios de pobreza. El Colegio de México.

Delgado, C. R., y Calero, C. G., 2017, "Espacios de convivencia y experiencia intergeneracional", en Trabajo Social Hoy, 82, 19-40. https://doi.org/10.12960/ TSH.2017.0014

Elias, 1989, "El envejecimiento y la muerte", en La soledad de los moribundos. México, DF, FCE.

Enríquez, P. G., 2007, "De la marginalidad a la exclusión social: un mapa para recorrer sus conceptos y núcleos problemáticos", en Fundamentos en humanidades, 8(15), pp. 57-88.

Flores, A., 2013, "Cuidado domiciliario y recuperación de la subjetividad: el caso de México", en Redistribuir el cuidado: el desafio de las políticas. Santiago: CEPAL, 2013. p. 423-453. LC/G. 2568-P.

Frávega, A., Carnino, M. A., Domínguez, N. y Bernal, C., 2008, “Adultos mayores y nuevas tecnologías: la superación de una brecha tecnológica”, en III Congreso de Tecnología en Educación y Educación en Tecnología.

INEGI, 2019, Encuesta Intercensal 2015. Bases de datos disponibles en https:// www.inegi.org.mx/programas/intercensal/2015/default.html\#Microdatos

González, K., 2015, "Envejecimiento demográfico en México: análisis comparativo entre las entidades federativas", en Conapo. La situación demográfica de México 2015. México: Consejo Nacional de Población, 113-129.

González, E., 2015, "Decisiones al final de la vida en México", en Entreciencias (3)8.

Grácida, E., 2004, “El desarrollismo”, UNAM-Océano. México.

Jiménez, A., 2011, "Paradojas de las abuelas que cuidan nietos y nietas. Entre el empoderamiento de sus hijas y la reproducción de roles tradicionales", en Memoria del $7^{\circ}$ Encuentro Nacional del Empoderamiento Femenino. Instituto de Ciencias Sociales y Humanidades. Universidad Autónoma de Hidalgo.

Jiménez, A., 2012, "Violencia en la vejez: el caso de las abuelas que cuidan a nietos y nietas en una localidad rural en el estado de Hidalgo", en El Cotidiano, 174(174), 19-32.

Klein, A., 2015, "La necesidad de cuidar de aquellos que solían necesitar ser cuidados: Vejez y tendencias familiares-demográficas", en Cultura y representaciones sociales, 10(19), 128-153.

Kuntz, S., 2012, Historia económica general de México. De la Colonia a nuestros días. México, El Colegio de México/Secretaría de Economía. 
Lozano, D., Martínez, A. y Montoya, B., 2019, "El sustrato significativo de las prácticas alimentarias, en el contexto de las políticas recientes ante el exceso de peso en México", en RLEEI (3)2. Abril-Junio 2019.

Luo, Y., LaPierre, T. A., Hughes, M. E. y Waite, L. J., 2012, “Grandparents providing care to grandchildren: A population-based study of continuity and change", en Journal of Family Issues, 33(9), 1143-1167.

Maldonado, M., 2015, "El rol de la abuela en el desarrollo de los nietos", en Mejía-Arauz, R. (coord.) Desarrollo psicocultural de niños mexicanos. Guadalajara, Jalisco: ITESO.

Margolis, R. y Wright, L., 2017, "Healthy grandparenthood: How long is it, and how has it changed?”, en Demography, 54(6), 2073-2099.

Martínez, C., 2012, "El muestreo en investigación cualitativa: principios básicos y algunas controversias", en Ciência \& Saúde Coletiva, 17, 613-619.

Martínez, M. y Rojas, O., 2016, "Una nueva mirada a la participación masculina en el trabajo doméstico y el cuidado de los hijos en México", en Estudios Demográficos y Urbanos, 31 (3), 635-662.

Morales, A. y Moreno, T., 2019, AMLO declara el fin de la política neoliberal. El Universal. 13 de marzo. Disponible en https://www.eluniversal.com.mx/nacion/ amlo-declara-el-fin-de-la-politica-neoliberal. Fecha de consulta 18/03/2019.

Morfín, T., y Sánchez, L., 2015, "Factores familiares y socioculturales en el desarrollo afectivo de niños y adolescentes mexicanos: su influencia en las conductas suicidas", en Mejía-Arauz, R. (coord.) Desarrollo psicocultural de niños mexicanos. Guadalajara, Jalisco: ITESO.

Ortiz, M., 2007, "La informática y el adulto mayor", en La ciencia y el hombre. XX (03) Septiembre-Diciembre. Disponible en https://www.uv.mx/cienciahombre/revistae/vol20num3/articulos/informatica/

Pacheco, E. y García, B., 2014, "Reflexiones sobre el estudio del uso del tiempo", en García B. y Pacheco E. (coord.) Uso del tiempo y trabajo no renumerado en México. El Colegio de México, ONU mujeres, Inmujeres.

Pebley, A. R. y Rudkin, L. L., 1999, "Grandparents Caring for Grandchildren: What Do We Know?”, en Journal of Family Issues, 20(2), 218-242. https://doi. org/10.1177/019251399020002003

Ramírez, P., 2012, “Ciudad y malestar social. Notas sobre la incertidumbre en la vida urbana contemporánea”, en Suárez, H., Zubillaga, V. y Bajoit, G. (coords.) El nuevo malestar en la cultura. México, UNAM, Instituto de Investigaciones Sociales. P.p. 194-214.

Rentería, E., Maldonado, C. y Lanza, B., 2007, “Abuelos y nietos, ¿una convivencia beneficiosa para los más jóvenes? El caso de Brasil y Perú", en Papeles de población, 13(52), 47-75. Recuperado de http://www.scielo.org.mx/scielo.php?script=sci_arttext\&pid=S1405-74252007000200003\&lng=es\&tlng=es, consultado el $24 / 03 / 2019$ 
Rivero E. y Hernández, A., 2014, "No todo el tiempo es igual: variaciones en los patrones de uso del tiempo en México", en García B. y Pacheco E. (coord.) Uso del tiempo y trabajo no renumerado en México. El Colegio de México, ONU mujeres, Inmujeres.

Robles, L., 2005, "La relación cuidado y envejecimiento: entre la sobrevivencia y la devaluación social", en Papeles de población, 11(45), 49-69.

Robles, L., 2006, "La vejez: nuevos actores, relaciones sociales y demandas políticas", en Relaciones. Estudios de historia y sociedad, 27(105).

Rodríguez M. y García, B., 2014, “Trabajo doméstico y de cuidado masculino", en García B. y Pacheco E. (coord.) Uso del tiempo y trabajo no renumerado en México. El Colegio de México, ONU mujeres, Inmujeres.

Rodríguez R. M., 2007, "Personas mayores y aprendizaje a lo largo de la vida de las tecnologías de la información y la comunicación", en Pixel-Bit. Revista de Medios y Educación, 30, 41-48.

Rojas, O. y Martínez, M., 2014, “Uso del tiempo en el ámbito doméstico entre los padres mexicanos", en García, Brígida y Pacheco, Edith (coords.) Uso del tiempo y trabajo no remunerado en México. México, El Colegio de México, 433-470.

Roo, J. B., Hamui, A., y Fernández, M., 2017, “Conflictos intergeneracionales en familias con abuelas cuidadoras", en Archivos en Medicina Familiar, 19(2), 43-52.

Rubio, G., y Garfias, F., 2010, Análisis comparativo sobre los programas para adultos mayores en México. CEPAL.

Santoyo, L. y Pacheco, E., 2014, "El uso del tiempo de las personas en México según tipo de hogar. Una expresión de las desigualdades de género", en García B. y Pacheco E. (coord.) Uso del tiempo y trabajo no renumerado en México. El Colegio de México, ONU mujeres, Inmujeres.

Seltzer, J. A., 2019, "Family Change and Changing Family Demography", en Demography, 1-22.

Strauss, A. y Corbin, J., 2002, Bases de la investigación cualitativa: técnicas y procedimientos para desarrollar la teoría fundamentada. Medellín,:UdeA.

Tellez, Y. y Muradas, M., 2018, "La dinámica demográfica de México, 19502015”, en Conapo, La situación demográfica de México 2017. México: Conapo.

Tuirán, R., 1993, Estrategias familiares de vida en época de crisis: El caso de México. Cepal.

Vasilachis, I., 2006, "La investigación cualitativa", en Vasilachis, I. (coord.) Estrategias de investigación cualitativa. Barcelona: Gedisa. Pp. 23-64.

Welti, C., 2018, "El Estado, la familia y el mercado. Arreglos institucionales para atender las necesidades generadas por el envejecimiento demográfico", en Papeles de Población, 24(95). 
Wooldridge, N., 2014, "Child and Preadolescent Nutrition", en Brown, J. Nutrition Through the Life Cycle. Cengage. Stanford.

Yanes, P., 2011, "La pensión ciudadana de adultos mayores en la Ciudad de México: Institucionalización de la universalidad y la no condicionalidad", en Las familias latinoamericanas interrogadas: hacia la articulación del diagnóstico, la legislación y las políticas. Santiago: CEPAL. 171-178.

Ybáñez, E., Vargas, E. y Torres, A. L., 2005, "Factores asociados a la corresidencia de los adultos mayores de 50 años por condición rural-urbana”, en Papeles de población, 11(45), 29-48.

\section{RESUMEN CURRICULAR DE LOS AUTORES}

\section{Alejandro Martínez Espinosa}

Sociólogo por la UNAM, maestro en Estudios de Población por El Colegio de la Frontera Norte y Doctor en Estudios de Población por El Colegio de México. Investigador posdoctoral en El Colegio de la Frontera Norte entre 2017 y 2018. En los artículos de su autoría se abordan los cambios contextuales, así como las características de los hogares, en su relación a las prácticas alimentarias de la población.

Dirección electrónica: amartineze@uaemex.mx

\section{Sergio Cuauhtémoc Gaxiola Robles Linares}

Actuario por la Facultad de Ciencias de la Universidad Nacional Autónoma de México. Maestro en Estudios de Población por la Facultad Latinoamericana de Ciencias Sociales (sede México). Doctor en Estudios de Población por El Colegio de México. Profesor de Tiempo Completo del Centro de Investigación y Estudios Avanzados de la Población de la Universidad Autónoma del Estado de México (UAEM) y miembro del Sistema Nacional de Investigadores (SNI). Docente en programas de licenciatura de la UAEM. Ha publicado varios artículos. Líneas de investigación: envejecimiento, mercados de trabajo y pobreza.

Dirección electrónica: serobles99@gmail.com

Artículo recibido el 27 de mayo de 2019 y aprobado el 24 de junio de 2019. 